\title{
A GEOGRAFIA ESCOLAR E AS TEMÁTICAS FÍSICO-NATURAIS NA BNCC desafios à prática docente e à formação de professores
}

Leonardo Ferreira Farias da Cunha ${ }^{1}$

\begin{abstract}
Resumo: A Base Nacional Comum Curricular (BNCC) fixa conteúdos mínimos para a educação básica brasileira e tem como objetivo ser a referência tanto para a construção de currículos como para a prática docente. Neste sentido, o presente texto tem por objetivo discutir a BNCC no Brasil, bem como analisar como os conteúdos de Geografia relacionados às temáticas físico-naturais aparecem neste documento. Para isso realizou-se uma análise documental focada nos objetivos deste marco legal e especialmente nas habilidades e competências esperadas para os anos finais do ensino fundamental, na disciplina de Geografia segundo tais temáticas. Foi possível concluir que os conteúdos relativos às temáticas físico-naturais no recorte analisado, não são claramente mencionados, nem podem ser facilmente deduzíveis a partir da BNCC, o que cria um desafio para professores e instituições formadoras.
\end{abstract}

Palavras-chave: BNCC. Geografia. Temáticas físico-naturais.

\section{LA GEOGRAFÍA ESCOLAR Y LAS TEMÁTICAS FISICO-NATURALES EN BNCC desafíos a la práctica docente y la formación de profesores}

Resumen: La Base Nacional Común Curricular (BNCC) fija contenidos mínimos para la educación básica brasileña y tiene como objetivo ser la referencia tanto para la construcción de currículos como para la práctica docente. En este sentido, el presente texto tiene por objetivo discutir la BNCC en Brasil, así como analizar cómo los contenidos de Geografía relacionados a las temáticas físico-naturales aparecen en este documento. Para eso se realizó un análisis documental enfocado en los objetivos de este marco legal y especialmente en las habilidades y competencias esperadas para los años finales de la enseñanza fundamental, en la disciplina de Geografía según tales temáticas. Es posible concluir que los contenidos relativos a las temáticas físico-naturales en el recorte analizado, no son claramente mencionados, ni pueden ser fácilmente deducibles a partir de la BNCC, lo que crea un desafío para profesores e instituciones formadoras.

Palabras clave: BNCC. Geografía. Temáticas físico-naturales.

\section{INTRODUÇÃO}

O Ministério da Educação (MEC) apresentou à população, em 2015, a Base Nacional Comum Curricular (BNCC), o documento em sua primeira versão foi submetido ao debate em diferentes eventos, instituições e a um período de consulta pública entre os

\footnotetext{
${ }^{1}$ Mestrando em Geografia pela Universidade de Brasília (UnB) na área de concentração em Gestão Territorial e Ambiental. Professor da Carreira do Magistério Público da Secretaria de Estado de Educação do Distrito Federal - SEEDF. Integra o grupo de pesquisa - Ensino, Aprendizagem e Formação de Professores em Geografia da Universidade de Brasília - GEAF/UnB. E-mail: leoffarias@ yahoo.com.br
} 


\section{REVISTA ELETRÔNICA \\ DA GRADUAÇÃO/PÓS-GRADUAÇÃO EM EDUCAÇÃO UFG/REJ}

\section{ITEERPUW REFLECTIONIS}

ISSN. 1807-9342

Volume 14, N. 2, 2018

meses de setembro de 2015 e março de 2016. Por meio de uma plataforma eletrônica as sugestões foram registradas no intuito de subsidiar uma segunda versão. Esta será encaminhada à especialistas para ser discutida e depois submetida ao Conselho Nacional de Educação.

É possível compreender a BNCC como um documento que surge para atender a uma demanda, a saber, a fixação de conteúdos mínimos para a educação básica, o que já estava previsto na Constituição Federal do Brasil no que se refere ao Ensino Fundamental, e mais tarde para o ensino médio, segundo o Plano Nacional de Educação. Outros documentos reforçam essa demanda, como a Lei de Diretrizes e Bases da Educação, as Diretrizes Curriculares Nacionais e os Parâmetros Curriculares Nacionais (PCN's). Dessa maneira a BNCC estabelece uma conexão filial ou complementar com os documentos antecedentes.

Esses precedentes que sinalizam certa coerência programática ao longo do tempo e a partir de marcos legais, não afastam a ideia de que o currículo é um instrumento com finalidades associadas a interesses, relações de poder, agentes hegemônicos, matrizes ideológicas e é também um campo de lutas (APPLE, 2016).

A BNCC é parte da Política Nacional de Educação Básica conduzida pelo MEC tendo como objetivo ser a referência para a construção e implementação de currículos para a educação básica bem como para os Projetos Políticos Pedagógicos das escolas (BRASIL, 2017). Essa política se desdobra em outras quatro: a de formação de professores, a de materiais e tecnologias educacionais, a de infraestrutura escolar e a de avaliação na educação básica que se articulam por meio das demandas oriundas da BNCC objetivando que haja segundo o órgão competente, uma melhoria da qualidade da Educação Básica brasileira.

Podemos inferir, assim, que essa qualidade pretendida, tem relação direta não só com o cumprimento dessa referência curricular, mas também, com a disponibilidade de uma infraestrutura adequada e da avaliação da mesma. Aliás, uma das funções da definição de uma base comum curricular ou de uma proposta curricular é poder, a partir dela, avaliar o desempenho dos estudantes, e assim atribuir juízo sobre a qualidade da educação. Configurando-se como um instrumento de controle uma vez que as propostas curriculares são historicamente protagonizadas pelo Estado e de forma verticalizada. 


\section{REVISTA ELETRÔNICA \\ DA GRADUAÇÃO/PÓS-GRADUAÇÃO EM EDUCAÇÃO \\ UFG/REJ}

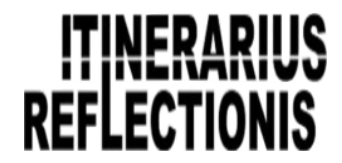

ISSN. 1807-9342

Volume 14, N. 2, 2018

Todavia, embora o cumprimento do currículo aponte um mecanismo de controle, a instituição do mesmo é algo dotado de importância pedagógica. Fazê-lo cumprir, ao menos no que se considera básico para uma sociedade, é parte relevante de uma política de educação. Sendo assim, o currículo em si não é um problema, mas o seu processo de construção, intenções e efetivação podem ser.

Sacristán (2000 p. 19) pontua que, o conjunto ou a seleção cultural "estruturada sob chaves psicopedagógicas" na qual se configura o currículo, é oferecido a fim de servir como projeto à instituição escolar e à medida que é construído preenche a escola de forma e conteúdo. Dessa maneira, toda a prática pedagógica orbita em torno do currículo, tornando-o no mínimo relevante.

Sobre o contexto em que surge a intenção de dar certa centralidade ao currículo é importante destacar que em meados dos anos 1990 Macedo (2011) comenta que havia um ambiente no Brasil que favorecia a ideia de centralização ou de uma base comum curricular. Essa circunstância se explicava por causas externas inerentes à relação diplomática com o Mercosul, e por influência de grupos econômicos instituições financeiras internacionais que tinham e tem a pretensão, de influenciar de algum modo a definição do currículo alinhando-o as demandas do mercado e da globalização (LIBÂNEO, 2012).

Na década de 1990 também surgem no país os Parâmetros Curriculares Nacionais (PCN's) reforçando ao menos em parte essas ideias de centralização, contudo, os PCN's se restringiram a sugestões curriculares, diferente da BNCC, que deverá servir como referência será o currículo mínimo prescrito. No início dos anos 2000, mesmo com a troca do governo no Brasil "as novas articulações políticas seguiram favoráveis à centralização curricular como forma de garantir a qualidade [social] da educação" (MACEDO, 2011, p.1534). Seguindo essa lógica, as Diretrizes Curriculares Nacionais e mais tarde o Plano Nacional de Educação reafirmaram a importância e a necessidade de se criar uma Base Nacional Comum Curricular.

Embora possam existir resistências ao estabelecimento de um currículo centralizado, a BNCC é uma realidade, até o presente momento para o ensino fundamental e mais tarde para o ensino médio. Surge com o papel de nortear a ação curricular e pedagógica tornando-se ponto de partida na construção de matrizes curriculares nos estados, nos municípios e no Distrito Federal. Com a iminência de sua implementação, é 


\section{REVISTA ELETRÔNICA \\ DA GRADUAÇÃO/PÓS-GRADUAÇÃO EM EDUCAÇÃO UFG/REJ}

\section{ITIMERARIIUS REFLECTIONIS}

ISSN. 1807-9342

Volume 14, N. 2, 2018

interessante discuti-la dando ênfase ao que se refere à Geografia, e em especial a parte deste que se relaciona às temáticas físico-ambientais atendem ao papel de orientadores da prática pedagógica no que concerne a esse recorte temático? A BNCC dará condições para que as instituições formadoras elaborem seus currículos contemplando a contento a área física da Geografia?

O presente texto discorrerá sobre essas questões por meio de uma análise documental da BNCC (terceira versão), em especial do que se propõe para o ensino fundamental anos finais, no componente curricular Geografia sobre as temáticas físiconaturais. Com enfoque nas competências, objetos de conhecimentos e nas habilidades que tratam dessas temáticas.

\section{AS COMPETÊNCIAS E AS HABILIDADES NA BASE NACIONAL COMUM CURRICULAR}

A Geografia no recorte analisado aparece no conjunto das Ciências Humanas e assim como as outras áreas de conhecimento apresentadas (Linguagens; Ciências da Natureza; Matemática; Ensino Religioso) possui um quadro de competências específicas. Para além dessas, há as competências específicas do componente, quando a área possui mais de um. Além das competências, o que se refere à Geografia está organizado em unidade temáticas às quais estão relacionados objetos de conhecimento e, por fim, as habilidades previstas para cada ano.

A BNCC elegeu o termo competência como fundamento pedagógico e reforça que o desenvolvimento das mesmas se dará:

Por meio de indicações claras do que os alunos devem saber (considerando a constituição de conhecimentos, habilidades e atitudes e valores) e, sobretudo, do que devem saber fazer (considerando a mobilização desses conhecimentos habilidades e atitudes e valores para resolver demandas complexas da vida cotidiana, do pleno exercício da cidadania e do mundo do trabalho), a explicitação das competências oferece referências para o fortalecimento das ações que assegurem as aprendizagens essenciais definidas na BNCC (BRASIL, 2017 p. 11).

Para Perrenoud (2013 p. 45) embora não se tenha um consenso sobre a definição de competência, elas compreendem "o poder de agir com eficácia em uma situação, mobilizando e combinando, em tempo real e de modo pertinente, os recursos intelectuais 


\section{REVISTA ELETRÔNICA \\ DA GRADUAÇÃO/PÓS-GRADUAÇÃO EM EDUCAÇÃO \\ UFG/REJ}

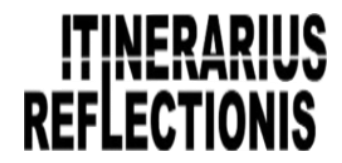

ISSN. 1807-9342

Volume 14, N. 2, 2018

e emocionais". Para este autor, elas são ao mesmo tempo, resultado de uma aprendizagem realizada e condição para a realização das atividades humanas. É pertinente citar também que Perrenoud (2013) reforça a ideia de que as competências são mais apropriadas a uma perspectiva de aplicação prática de conhecimentos, uma aprendizagem para a vida.

As competências, na perspectiva do currículo, não são sinônimos dos conteúdos, mas, obviamente a descrição delas pode sugerir a mobilização destes. Sobre isso Primi et al. (2001 p. 157) em um artigo que tratam de habilidades e competências afirmam que nas abordagens sobre inteligência duas estruturas são muito importantes: "a inteligência cristalizada (que prioriza o conhecimento) e inteligência fluida (que prioriza o raciocínio)". Enquanto a primeira se relaciona ao repertório de conhecimentos e informações acumulados durante a vida escolar, a segunda refere-se à capacidade cognitiva de processar informações e fazer relações, a partir da bagagem de conhecimento que se possui.

A Lei de Diretrizes e Bases da Educação (13.415/2017) recentemente alterada sobretudo pela denominada reforma do Ensino Médio, utiliza nomenclaturas como direitos e objetivos de aprendizagem, além das já mencionadas habilidades e competências. A própria BNCC em referência a elas, afirma em sua introdução: "Tratase, portanto, de maneiras diferentes e intercambiáveis para designar algo comum, ou seja, aquilo que os estudantes devem aprender na Educação Básica, incluindo tanto os saberes quanto a capacidade de mobilizá-los e aplicá-los” (BRASIL, 2017 p.10).

Contudo, o que os estudantes devem aprender e os saberes a serem mobilizados não aparecem a contento nas habilidades e competências atribuídas à Geografia. Priorizar o desenvolvimento de competências e não a transmissão de conhecimentos é uma perspectiva muito presente nos estudos sobre currículo. Os que advogam em prol desta ideia afirmam que uma referência sob estas bases não deve mais definir o que será ensinado, mas as competências a serem construídas, Costa (2005). Entretanto, numa relação de ensino-aprendizagem o alcance dessas competências exigirá vários conhecimentos, de conteúdo, ainda que não estejam explicitados.

Surge assim, o imponderável o imprevisível. Não é possível dizer os conteúdos que devem ser ensinados para alcançar as expectativas das competências e habilidades. Caberá ao professor deduzir. Diante disso é possível questionar: Apesar das diferentes possibilidades de conteúdos e conceitos, há alguns indispensáveis? Acredita-se que sim. 


\section{REVISTA ELETRÔNICA \\ DA GRADUAÇÃO/PÓS-GRADUAÇÃO EM EDUCAÇÃO \\ UFG/REJ}

\section{ITWERAPUS REFLECTONIS}

ISSN. 1807-9342

Volume 14, N. 2, 2018

Quando se ensina o componente espacial relevo, por exemplo, a ideia de processo vinculada à morfogênese e a morfodinâmica precisa estar presente? Será que todos os professores considerarão ao menos esta ideia como essencial? Uma referência curricular nacional deveria informar?

Young (2014) coloca que o acesso ao conhecimento, legitimado pelo currículo, é fundamental para uma justiça educacional, compreende uma política de justiça social e maior igualdade. Se a BNCC surge com o objetivo de promover igualdade de acesso ao conhecimento mínimo, talvez a vagueja e a omissão de quais conteúdos devem ser ensinados impeça que esse objetivo se concretize.

Vejamos as competências a seguir.

\section{Quadro 1. Competências relativas às temáticas físico-naturais presentes na BNCC.}

\begin{tabular}{|c|c|}
\hline $\begin{array}{l}\text { COMPETÊNCIA GERAL RELATIVA ÀS } \\
\text { CIÊNCIAS HUMANAS. }\end{array}$ & $\begin{array}{c}\text { COMPETÊNCIAS ESPECÍFICAS DE } \\
\text { GEOGRAFIA PARA O ENSINO } \\
\text { FUNDAMENTAL }\end{array}$ \\
\hline $\begin{array}{l}\text { Identificar, comparar e explicar a intervenção do } \\
\text { ser humano na natureza e na sociedade, } \\
\text { exercitando a curiosidade e propondo ideias e } \\
\text { ações que contribuam para a transformação } \\
\text { espacial, social e cultural, de modo a participar } \\
\text { efetivamente das dinâmicas da vida social. }\end{array}$ & $\begin{array}{l}\text { Utilizar os conhecimentos geográficos para } \\
\text { entender a interação sociedade/ natureza e } \\
\text { exercitar o interesse e o espírito de investigação e } \\
\text { de resolução de problemas. }\end{array}$ \\
\hline
\end{tabular}

Fonte: Base Nacional Comum Curricular (BRASIL, 2017).

No quadro 1 são apresentadas duas competências da BNCC $3^{\mathrm{a}}$ versão, uma geral aplicável a todas as Ciências Humanas e outra específica da Geografia. Ambas incluem a capacidade de propor ideias e ações que visão resolver problemas relacionados à relação que os seres humanos estabelecem com o meio ambiente. Embora não explicitados, há muitos conteúdos possíveis nestas habilidades. Isso seria problema para uma proposta curricular?

Sendo assim, cabe ao operador do currículo em consonância com as competências supracitadas deduzir quais conhecimentos são necessários para desenvolvê-los? Diante disso, poderia se questionar que talvez eles não tenham sido mencionados, justamente para que o currículo não seja apresentado puramente como seleção ou programa? Mas o 


\section{REVISTA ELETRÔNICA \\ DA GRADUAÇÃO/PÓS-GRADUAÇÃO EM EDUCAÇÃO \\ UFG/REJ}

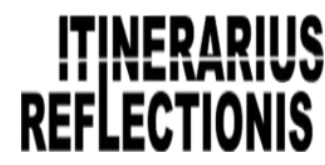

ISSN. 1807-9342

Volume 14, N. 2, 2018

questionamento que se põe é outro: o que se apresenta é uma omissão ou uma perspectiva mais flexível que valoriza a autonomia do professor?

Como o alcance dessas competências e habilidades irão demandar a ação mediadora do professor e sua capacidade de seleção e organização de conteúdos dentro do campo de conhecimento da disciplina, a base por si não resolve a questão. A resposta a esse documento pode ser diversa, devido as diferenças sociais, institucionais, políticas, econômicas, além de distintas trajetórias de vida, de formação inicial e continuada dos professores, bem como de todos os elementos complexos do fazer docente que são, em muitos casos, externos à decisão do professor.

Os conteúdos não estão claramente, ou não são mencionados no texto da BNCC, uma vez que o documento em tela apresenta expectativas de aprendizagens e não os conteúdos em si. Essa preocupação pode parecer desnecessária, conteudista - no sentido de valorização irrefletida dos mesmos - ou até fruto de uma cultura de educação informativa ou bancária (FREIRE, 1997). Entretanto, o que nos move a discutir os conteúdos é a consideração de sua importância no que concorre para a função da escola, a saber, a transmissão do conhecimento. Com o envolvimento ativo do aprendiz no processo de aquisição do mesmo, o conhecimento poderoso, que pode "capacitar jovens a adquirir o conhecimento que, para a maioria deles, não pode ser adquirido em casa ou em sua comunidade, e para adultos, em seus locais de trabalho" (YOUNG, 2007 p. 1293 1294), independente das particularidades dos alunos e professores neste país imenso e diverso que é o Brasil.

Os conteúdos são importantes, pois, fornecem elementos básicos mínimos à compreensão da realidade, e numa perspectiva geográfica, da própria espacialidade dos fenômenos e objetos. Embora os alunos sempre apresentem uma visão de mundo ainda que sincrética e baseada no senso comum, cabe à escola enquanto instituição que se destina a promover educação, superar essa visão inicial e avançar na construção de conhecimentos científicos a partir inclusive desta bagagem prévia. Neste sentido, segundo Cavalcanti (2013 p.148) "levar em conta o mundo vivido dos alunos implica apreender seus conhecimentos prévios e sua experiência em relação ao assunto estudado", para desse modo avançar para um conhecimento mais sistematizado, ao processo de construção de conceitos. 


\section{REVISTA ELETRÔNICA \\ DA GRADUAÇÃO/PÓS-GRADUAÇÃO EM EDUCAÇÃO \\ UFG/REJ}

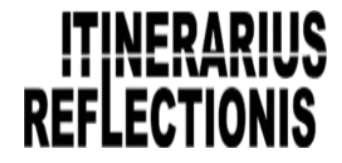

ISSN. 1807-9342

Volume 14, N. 2, 2018

Young e Muller (2016) ao analisar cenários futuros para a educação e, por conseguinte, concepções curriculares e pedagógicas, aponta que um cenário ideal e com efetivo avanço caracteriza-se quando o currículo vai além de habilidades e preconiza uma progressão conceitual. Estipulações curriculares baseadas em conceitos obrigatoriamente envolvem conteúdos, ou seja, aquilo que está sendo conceitualizado. No entanto, ocorre que o que se pratica geralmente segundo Young e Muller (2016) é que mesmo em disciplinas ricas em conceitos os currículos se apresentam subestipulados e os professores se ressentem da falta de sinais claros nestes currículos e ficam para trás sem perceberem, ou ignoram passos conceituais que mais tarde mostrar-se-ão vitais.

Dessa maneira os conteúdos, a saber, os conceitos estruturantes e as categorias elementares que toda ciência postula, precisam ser claramente apresentados quando numa proposta curricular, sobretudo se essa proposição pretende ser comum e servir de base. Esse entendimento não se dá no sentido de que o professor não tem autonomia para fazer as escolhas se o currículo não os menciona objetivamente, mas para reforçar que a tendência presente na atual conjuntura de reduzir o currículo a objetivos, competências e habilidades pode criar distorções a depender do contexto de aplicação. Young e Muller afirmam ainda que:

\footnotetext{
"Essas tendências não constituem obstáculos intransponíveis para escolas com bons recursos, que são capazes de contratar professores com fortes qualificações em suas disciplinas, que podem preencher as lacunas. Elas são, entretanto, um problema inevitável para as escolas que atendem comunidades pobres, que não conseguem atrair tais professores" (YOUNG E MULLER, 2016 P.545).
}

Neste sentido, reforçamos a importância dos conteúdos e dos conceitos e/ou porque é desejável que eles apareçam nas propostas curriculares ao menos com uma clareza ou necessidade epistêmica de ação. Portanto, reconhecemos que embora importantes os conteúdos não sejam um fim em si mesmos, mas elementos mediadores no caso da geografia - da compreensão de uma dada organização e característica espacial (ASCENÇÃO; VALADÃO, 2013), ensiná-los a contento é imprescindível. Retomando a citação acima todas as escolas estão conseguindo alcançar este objetivo?

Sendo assim, essa omissão deliberada ou não, questionada ou não, é um problema, não só para o professor no seu planejamento didático como também para as instituições 


\section{REVISTA ELETRÔNICA \\ DA GRADUAÇÃO/PÓS-GRADUAÇÃO EM EDUCAÇÃO \\ UFG/REJ}

\section{ITINEPRARIIUS REFLECTIONIS}

ISSN. 1807-9342

Volume 14, N. 2, 2018

formadoras que, tomando um caminho não desejável, podem optar por uma formação mais sintética e superficial, julgando terem atendido à demanda do marco regulatório (MACHADO, 2013)

Se todos os professores do Brasil tivessem uma boa formação inicial e continuada, o que sabe-se não ocorrer (GATTI, 2016), e no que se refere a essas temáticas não há exceção (MORAIS, 2011) a identificação e seleção dos conteúdos para alcançar as competências e habilidades propostas pela $\mathrm{BNCC}$, ocorreriam sem maiores dificuldades e até com certa coerência, posto que não são necessariamente, mal elaboradas. Portanto, dada a complexidade do quadro formativo, um currículo baseado em competências e habilidades pode não concretizar aprendizagens, tampouco efetivar o ensino dos conteúdos capazes de trazê-las a existência. Como aponta Young e Muller (2016) conceitos, habilidades e conteúdo são todos importantes e devem ser estipulados no currículo.

No quadro 2 estão apresentados os objetos de conhecimento, que junto com as habilidades e competências são as referências para a escolha do conteúdo a ser trabalhado. Percebe-se a generalização das colocações, o que revela ainda que o operador deste documento que parece ser um currículo mínimo, escolherá o conjunto de conteúdos para trabalhar com esses objetos. Desse modo, sabendo que a BNCC agora é uma diretriz para todos os currículos da educação básica e superior (no caso das licenciaturas) do Brasil. Seus propositores poderiam ter apresentado uma relação dos conteúdos possíveis, próximos, adequados às expectativas de aprendizagem ainda que num documento anexo. Indo além, por exemplo, dos termos como sociedade e natureza ou sinônimos igualmente abrangentes como fenômenos naturais, atividades humanas, paisagem natural e diversidade ambiental.

\section{Quadro 2. Objetos de conhecimento da Geografia para o Ensino Fundamental anos finais relacionados às temáticas físico-naturais.}

\begin{tabular}{|c|c|c|c|c|}
\hline & $6^{\circ}$ ano & $7^{\circ}$ ano & $8^{\circ}$ ano & $9^{\circ}$ ano \\
\hline $\begin{array}{c}\text { Objetos de } \\
\text { conhecimento }\end{array}$ & $\begin{array}{l}\text { * Relações entre os } \\
\text { componentes físico- } \\
\text { naturais; } \\
\text { *Transformação das } \\
\text { paisagens naturais e } \\
\text { antrópicas; }\end{array}$ & $\begin{array}{l}\text { *Biodiversidade } \\
\text { brasileira. }\end{array}$ & $\begin{array}{l}\text { *Diversidade } \\
\text { ambiental e as } \\
\text { transformações } \\
\text { nas paisagens na } \\
\text { América Latina }\end{array}$ & $\begin{array}{l}\text { *Cadeias industriais } \\
\text { e inovação no uso } \\
\text { dos recursos } \\
\text { naturais e matérias- } \\
\text { primas }\end{array}$ \\
\hline
\end{tabular}


REVISTA ELETRÔNICA

DA GRADUAÇÃO/PÓS-GRADUAÇÃO EM EDUCAÇÃO

UFG/REJ

\section{ITNEPAPIIS REFLETIONIS}

ISSN. 1807-9342

Volume 14, N. 2, 2018

\section{*Biodiversidade e ciclo hidrológico; \\ *Fenômenos naturais e sociais representados de diferentes maneiras; \\ *Atividades humanas e dinâmica climática.}

Fonte: Base Nacional Comum Curricular (BRASIL, 2017).

A clareza em um documento curricular sobre os possíveis conteúdos a se requisitar numa habilidade (ao menos um conjunto no qual se escolhe aquele que o professor mais se identifica), reforça o uso de conceitos científicos na mediação dos mesmos, além de impedir que o senso comum ganhe mais espaço do que o adequado na prática docente. Operacionalizar a competência ou uma habilidade correlata se faz voltado à prática social, mas com base nos conhecimentos científicos apreendidos. Caso contrário qual o papel da escola?

\section{AS TEMÁTICAS FÍSICO-NATURAIS NAS HABILIDADES PREVISTAS NA BASE NACIONAL COMUM CURRICULAR}

Quando as habilidades se referem às temáticas físico-ambientais e às dinâmicas do sistema terrestre, são usados termos como "natureza" ou "ambiente" para se referir a todos os processos pertinentes à dinâmica do sistema terrestre.

No quadro 3 as habilidades que se referem aos recursos hídricos e dinâmica climática trazem uma maior clareza dos possíveis conteúdos a serem ensinados como o ciclo hidrológico, rede hidrográfica, bacia hidrográfica e sua morfologia, manejo de recurso hídrico, relação entre movimentos terrestres e a distribuição dos tipos climáticos. Em contrapartida as habilidades que tratam da modificação das paisagens não acenam a nenhum conteúdo geográfico a ser mobilizado, fica um vazio que permite diferentes direções ou nenhuma mais consistente. A habilidade discutida não é ruim, mas não há indicações mínimas dos conteúdos mais pertinentes a essa problematização. 


\section{REVISTA ELETRÔNICA \\ DA GRADUAÇÃO/PÓS-GRADUAÇÃO EM EDUCAÇÃO \\ UFG/REJ}

Quadro 3. Habilidades esperadas para $06^{\circ}$ ano ligadas à área física da Geografia.

\begin{tabular}{|l|l|l|l|}
\hline \multicolumn{2}{|c|}{ Habilidades de Geografia relativas às temáticas físico-naturais para o Ensino Fundamental } \\
anos finais: 6o ano
\end{tabular}

Fonte: Base Nacional Comum Curricular (BRASIL, 2017).

\section{Quadro 4. Habilidades esperadas para o $7^{\circ}$ ano ligadas à área física da Geografia.}

\begin{tabular}{|c|c|}
\hline \multicolumn{2}{|c|}{$\begin{array}{l}\text { Habilidades de Geografia relativas às temáticas físico-naturais para o Ensino } \\
\text { Fundamental anos finais: } 7^{\circ} \text { ano }\end{array}$} \\
\hline $\begin{array}{l}\text { * Caracterizar dinâmicas dos componentes físico- } \\
\text { naturais no território nacional, bem como sua } \\
\text { distribuição e biodiversidade (Florestas } \\
\text { Tropicais, Cerrados, Caatingas, Campos Sulinos } \\
\text { e Matas de Araucária). }\end{array}$ & $\begin{array}{l}\text { *Comparar unidades de conservação existentes no } \\
\text { Município de residência e em outras localidades } \\
\text { brasileiras, com base na organização do Sistema } \\
\text { Nacional de Unidades de Conservação (SNUC). }\end{array}$ \\
\hline
\end{tabular}

Fonte: Base Nacional Comum Curricular (BRASIL, 2017).

No sétimo ano (quadro 4) há apenas duas habilidades vinculadas a área física da Geografia, uma mais diretamente e que refere às dinâmicas físico-naturais do território brasileiro e sua biodiversidade, e outra não tão direta que propõe o exercício da comparação de unidades de conservação. Na primeira há menção a tipos vegetacionais, mas caberia conhecimentos científicos úteis a abordagem da Geografia, como a geomorfologia, a climatologia, a hidrografia, a biogeografia e em cada um desses, diferentes desdobramentos. O que fazer fica a cargo de cada professor.

Seria importante indicar conteúdos cabíveis (ressignificados), pois é impossível que os alunos consigam realizar tal habilidade sem essa abordagem de múltiplas perspectivas. A segunda é mais objetiva e pode ser trabalhada tal qual a descrição. Por fim, parece que todo o conteúdo referente a área física da Geografia no sétimo ano, não pode ser depreendido partir destas duas habilidades apresentadas. 


\section{REVISTA ELETRÔNICA \\ DA GRADUAÇÃO/PÓS-GRADUAÇÃO EM EDUCAÇÃO \\ UFG/REJ}

Quadro 5. Habilidades esperadas para o $8^{\circ}$ ano ligadas à área física da Geografia.

\section{Habilidades de Geografia relativas às temáticas físico-naturais para o Ensino} Fundamental anos finais: $8^{\circ}$ ano

*Identificar paisagens da América Latina e associá-las, por meio da cartografia, aos diferentes povos da região, com base em aspectos da geomorfologia, da biogeografia e da climatologia.

*Analisar características de países e grupos de países da América e da África no que se refere aos aspectos populacionais, urbanos, políticos e econômicos, e discutir as desigualdades sociais e econômicas e as pressões sobre a natureza e suas riquezas (sua apropriação e valoração na produção e circulação), o que resulta na espoliação desses povos.
*Analisar o papel ambiental e territorial da Antártica no contexto geopolítico, sua relevância para os países da América do Sul e seu valor como área destinada à pesquisa e à compreensão do ambiente global.

* Analisar a importância dos principais recursos hídricos da América Latina (Aquífero Guarani, Bacias do rio da Prata, do Amazonas e do Orinoco, sistemas de nuvens na Amazônia e nos Andes, entre outros) e discutir os desafios relacionados à gestão e comercialização da água.

*Identificar os principais recursos naturais dos países da América Latina, analisando seu uso para a produção de matéria-prima e energia e sua relevância para a cooperação entre os países do Mercosul.

Fonte: Base Nacional Comum Curricular (BRASIL, 2017).

Para o oitavo ano (quadro 5) as habilidades apresentam mais elementos indicadores dos conteúdos, sobretudo nas que se referem às paisagens da América Latina, embora entenda-se que seja melhor que o conteúdo apareça em combinação com as habilidades e as competências. Se um currículo só com habilidade e competências não é o ideal, um que tenha só conteúdos também não o será. O esforço não pode ser demasiado para um ou para outro, todavia a combinação de ambos será melhor tanto em termos epistemológicos quanto de justiça social (YOUNG, 2007).

No nono ano (quadro 6), permanecem algumas generalizações reforçando o que (SOUZA, 2016 P. 425) afirmou como superficialidades, vagueza e falta de clareza, chegando a afirmar que "está ausente a proposição dos conteúdos".

Quadro 6. Habilidades esperadas para $09^{\circ}$ ano ligadas à área física da Geografia.

\begin{tabular}{|c|c|}
\hline \multicolumn{2}{|c|}{$\begin{array}{c}\text { Habilidades de Geografia relativas às temáticas físico-ambientais para o Ensino Fundamental } \\
\text { anos finais: } 9^{\circ} \text { ano }\end{array}$} \\
\hline $\begin{array}{l}\text { * Relacionar diferenças de paisagens aos modos } \\
\text { de viver de diferentes povos na Europa, Ásia e } \\
\text { Oceania, valorizando identidades e } \\
\text { interculturalidades regionais. } \\
\text { *Analisar os componentes físico-naturais da } \\
\text { Eurásia e os determinantes histórico-geográficos } \\
\text { de sua divisão em Europa e Ásia. } \\
\text { *Analisar características de países e grupos de } \\
\text { países europeus, asiáticos e da Oceania em seus }\end{array}$ & $\begin{array}{l}\text { *Identificar e comparar diferentes domínios } \\
\text { morfoclimáticos da Europa, da Ásia e da Oceania. } \\
\text { *Explicar as características físico-naturais e a forma } \\
\text { de ocupação e usos da terra em diferentes regiões da } \\
\text { Europa, da Ásia e da Oceania. *Identificar e analisar } \\
\text { as cadeias industriais e de inovação e as } \\
\text { consequências dos usos de recursos naturais e das } \\
\text { diferentes fontes de energia (tais como }\end{array}$ \\
\hline
\end{tabular}




\section{REVISTA ELETRÔNICA

aspectos populacionais, urbanos, políticos e termoelétrica, hidrelétrica, eólica e nuclear) em econômicos, e discutir suas desigualdades sociais diferentes países.

e econômicas e pressões sobre seus ambientes

físico-naturais.

Fonte: Base Nacional Comum Curricular (BRASIL, 2017).

A visão de que a sociedade e a natureza são intrínsecas à análise geográfica até aparece na apresentação da disciplina de Geografia, bem como categorias e conceitos, mas a BNCC ao expor as competências e sobretudo as habilidades sem a clareza de quais conteúdos, em especial os que concernem às temáticas físico-ambientais, cria um problema. Tais conteúdos, precisam estar articulados para proceder à análise e, consequentemente, alcançar os objetivos.

Essas habilidades como supracitado dizem respeito à relação sociedade / natureza, mas não de qual (is) modo (s) pode-se encaminhar a discussão nem quais temáticas físicoambientais além de natureza e ambiente. É importante destacar que não se pretende reforçar qualquer divisão dentro da ciência tampouco dentro da Geografia Escolar quando falamos desses temas vinculados ao que convencionou chamar de Geografia Física. O que interessa de fato é ressaltar como as temáticas físico-naturais são importantes no entendimento do espaço geográfico, onde se vive e como elas estão presentes nas espacialidades, como podem ser apreendidas por meio da educação geográfica, o que implica reflexão sobre os conteúdos e seu tratamento (CALLAI, 2015).

Sobre o que se espera do que se convencionou chamar Geografia Física, Nunes (2015) pontua que,

O que se espera é que a Geografia, em especial a Geografia Física, construa uma visão plena dos processos de produção da natureza, onde natureza e sociedade sejam integradas, independente da verticalização do tema, ou do recorte espacial, a serem adotados nos estudos geográficos (p.128).

A visão plena a que se refere o autor acima está intrinsecamente ligada à capacidade de mobilizar conhecimentos da área física da Geografia. Nesse sentido a apresentação das habilidades sem os conteúdos, ainda que mínimos, cria no contexto brasileiro um nó. À medida que este currículo for aplicado, as ausências próprias da formação docente inicial e continuada, evidenciarão uma condição de desencontros entre o que se espera o que será efetivamente realizado (MORAIS, 2011). Somam-se a isso as 


\section{REVISTA ELETRÔNICA \\ DA GRADUAÇÃO/PÓS-GRADUAÇÃO EM EDUCAÇÃO \\ UFG/REJ}

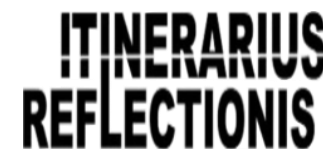

ISSN. 1807-9342

Volume 14, N. 2, 2018

desiguais condições de trabalho existentes no Brasil e que influenciam fortemente a relação ensino-aprendizagem.

O levantamento das habilidades relativas às temáticas físico-ambientais revela uma omissão típica dos currículos baseados em competências e habilidades. O receio de ferir a autonomia docente e o respeito à diversidade acabam por gerar um currículo que não exige conhecimentos mínimos, assim, o básico e comum podem virar 'um pastel de vento'.

\section{A BNCC COMO REFERÊNCIA PARA A FORMAÇÃO DOCENTE E A DISCUSSÃO DO CURRÍCULO}

Um profissional bem formado é dever do Estado e direito dos alunos. Morais (2013) e Ascenção e Valadão (2013) ressaltam a importância da solidez de uma formação inicial e continuada, contribuindo para que os saberes docentes ou da docência sejam aprimorados, sobretudo no que se refere ao conteúdo, especificamente os saberes didáticos do conteúdo conforme Shulman (2005)

Quanto à formação de professores de Geografia, Guimarães (2015) pontua que:

A construção de um ensino de geografia qualificado, significativo e criativo é uma meta que depende fundamentalmente de um processo de formação que seja capaz de desenvolver o talento, o desenvolvimento e o domínio das diversas dimensões que abarcam o ofício de professor. Tal tarefa demanda a formação continuada desse profissional e enfoca principalmente professores que não desistam de sua capacidade de aprendiz, que problematizem a sua experiência, o seu desenvolvimento profissional/pessoal e a sua constituição identitária (p.36).

A formação a que refere a autora, pode ou não existir por conta das dificuldades já mencionadas. A partir disso, questionar a clareza de orientações curriculares se torna importante, pois, nesse contexto de lacunas e deficiências a omissão de um documento que se põe como referência, ao invés de trabalhar contra essas ausências, pode ampliar as suas consequências.

Sobre os grandes desafios da educação Kaercher (2016) no parecer crítico que fez antes da divulgação da segunda versão da BNCC, aponta que o que deveria anteceder a discussão dos conteúdos e das metodologias, é uma discussão da infraestrutura escolar, 


\section{REVISTA ELETRÔNICA \\ DA GRADUAÇÃO/PÓS-GRADUAÇÃO EM EDUCAÇÃO \\ UFG/REJ}

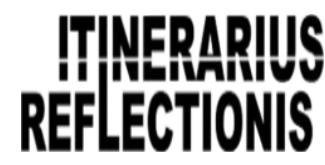

ISSN. 1807-9342

Volume 14, N. 2, 2018

da valorização do professor, e de sua real inserção no debate decisórios de sua área de atuação, posto que, certamente é mais fácil discutir ou tentar resolver a educação via currículo do que as questões estruturais. Ele compreende que, embora a BNCC não se proponha a resolver essas questões, deve contribuir com essa discussão.

A discussão da Base Nacional Comum Curricular pode colaborar com uma prática negligenciada ou pelo menos pouco valorizada nos cursos de licenciatura, a discussão do currículo. Embora as questões estruturais sejam sempre muito inibidoras de outras ações mais subjetivas, esse tema precisa ocupar parte das discussões e das aulas nos cursos de formação de professores.

Pinheiro (2015) e Macedo (2011) informam que na academia a discussão do tema currículo não é recente, contudo, para Pinheiro (op cit) ter os documentos de referência não é o problema, já que eles existem para diferentes níveis e aplicações. No entanto, é preciso agir sobre e a partir desses documentos curriculares, ainda que motivados por opiniões divergentes, pois o currículo é um campo de atuação política, assim como a disciplina é uma condição política de valorização e reafirmação de sua relevância (ROCHA, 2012). A BNCC reascendeu a discussão sobre as diretrizes curriculares nacionais assim como revisita aos Parâmetros Curriculares Nacionais, isso é novo de algum modo e convoca impessoalmente os estudantes de licenciatura e professores a pensar no currículo.

\section{CONSIDERAÇÕES FINAIS}

Os conteúdos e conceitos relativos às dinâmicas físico-naturais são imprescindíveis ao êxito das expectativas de aprendizagem no que se refere à Geografia Escolar. Mesmo sendo o Brasil tão territorialmente extenso e ambientalmente diverso, alguns postulados sobre funcionamento da natureza sempre serão úteis, independente da localização. Contudo, nem sempre estes estão presentes nas competências e habilidades das propostas curriculares, ou, delas podem emergir.

A BNCC, como orientadora das matrizes curriculares e da formação docente, tal como está, pode dar margem a desdobramentos muito diversos, com configurações formativas mais densas ou bem mais aligeiradas. Isto pode ser conveniente às iniciativas mercenárias que não escapam ao campo educacional. Atualmente, a maioria das instituições formadoras de professores é da iniciativa privada e em grande medida, 


\section{REVISTA ELETRÔNICA \\ DA GRADUAÇÃO/PÓS-GRADUAÇÃO EM EDUCAÇÃO UFG/REJ}

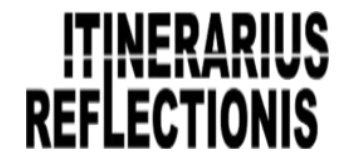

ISSN. 1807-9342

Volume 14, N. 2, 2018

ofertam cursos por meio da modalidade de Ensino a distância (EAD). Esta modalidade embora tenha a sua importância, sobretudo, num país continental como nosso não deixa de ser também uma maneira de baratear custos e acelerar a formação.

Reconhecemos que o currículo é um campo de atuação, inclusive política, que a disciplina é também uma condição política que viabiliza sua própria existência como componente curricular. Na concepção do currículo, não há neutralidade no processo, pois, ele sempre atende a objetivos, mais ou menos explícitos. Sua função é validar alguma ideia seja afirmação ou omissão. Dessa maneira, acreditamos que em prol do bom exercício da Geografia na Educação Básica é importante que um marco legal como a BNCC não se limite a um conjunto de competências e habilidades, mas que reforce a necessidade de acenar ao menos alguns conteúdos e conceitos próprios, como os relativos às dinâmicas físico-ambientais, valorizando o domínio teórico e conceitual dos geógrafos professores nesse aspecto.

Entendemos que a análise espacial ou da espacialidade, ganha substância quando as temáticas físico-naturais são trabalhadas por meio de princípios físicos e naturais. Que os conhecimentos sistematizados pela Geomorfologia, pela Climatologia, pela Geologia, pela Hidrografia, pela Biogeografia entre outros, ainda que ressignificados e devidamente dimensionados para a Educação básica, devem em alguma medida compor o repertório curricular da Geografia. Apropriar-se desse repertório é crucial para tornar o aluno mais capaz ou habilidoso para ler a realidade à sua volta, especialmente de modo geográfico.

\section{REFERÊNCIAS}

APPLE, M. W. Ideologia e currículo. Artmed Editora, 2016.

ASCENÇÃO, V. de O. R. e VALADÃO, R. C. A abordagem do conteúdo relevo na educação básica. In: CAVALCANTI, Lana de Souza. (org.) Temas da geografia na Escola Básica. $1^{a}$ edição. Papirus, 2013.

FREIRE, P. Educação “bancária” e educação libertadora. Introdução à psicologia escolar, v. 3, 1997.

GATTI, B. A. Formação de professores: condições e problemas atuais. REVISTA INTERNACIONAL DE FORMAÇÃO DE PROFESSORES, v. 1, n. 2, 2016.

GUIMARÃES, I. V. Questões sobre a formação de professores de geografia. In: RABELO, K. S. de P; BUENO, M. A. Currículo, Políticas Públicas e ensino de Geografia. Goiânia: Ed. Da PUC de Goiás, 2015. 


\section{REVISTA ELETRÔNICA \\ DA GRADUAÇÃO/PÓS-GRADUAÇÃO EM EDUCAÇÃO \\ UFG/REJ}

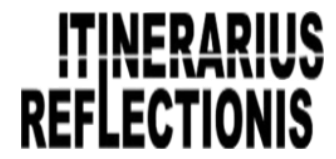

ISSN. 1807-9342

Volume 14, N. 2, 2018

KAERCHER, N. A. Pode a BNCC ajudar a atrair o aluno para a escola, manter seu interesse e fazer com que ele aprenda? Como a BNCC pode ajudar a romper a desesperança dos professores?. Pareceres de Leitores Críticos.

In:http://basenacionalcomum.mec.gov.br/documentos/relatóriosanaliticos/pareceres/Nes tor_Andre_Kaercher.pdf. acesso em 20/05/2016.

LIBÂNEO, J. C. O dualismo perverso da escola pública brasileira: escola. Educação e Pesquisa, v. 38, n. 1, p. 13-28, 2012.

MACEDO, E. Base Nacional Curricular Comum: novas formas de sociabilidade produzindo sentidos para educação. Revista Científica e-Curriculum, v. 12, n. 3, p. 1530-1555, 2014.

MACHADO, M. P. O pacto neodesenvolvimentista e as políticas de expansão da educação superior no Brasil de 2003 a 2013. Tese de Doutorado. Setor de Educação da Universidade Federal do Paraná. 2013.

MENDONÇA, F. Geografia socioambiental. Terra Livre, n. 16, p. 113-132, 2001.

MORAIS, E. M. B. de. (2011). As temáticas físico-naturais como conteúdo no ensino de geografia escolar. In: CAVALCANTI, Lana de Souza. (org.) Temas da geografia na Escola Básica. $1^{a}$ edição. Papirus, 2013.

MORAIS, E. M. B. de. O ensino das temáticas físico-naturais na Geografia escolar. 2011. Tese de Doutorado. Universidade de São Paulo.

MINISTÉRIO DA EDUCAÇÃO. Base Nacional Comum Curricular - Proposta preliminar $3^{\mathrm{a}}$ versão. Dezembro 2017.

NUNES, J. O. R. et al. A influência dos métodos científicos na Geografia Física. Terra Livre, v. 2, n. 27, p. 121-132, 2015.

PERRENOUD, P. Desenvolver competências ou ensinar saberes?: A escola que prepara para a vida. Penso Editora, 2013.

PINHEIRO, A. C. Reformas curriculares, políticas públicas e o ensino de geografia. In: RABELO, K. S. de P; BUENO, M. A. Currículo, Políticas Públicas e ensino de Geografia, Goiânia: Ed. Da PUC de Goiás, 2015.

PRIMI, R. et al. Competências e habilidades cognitivas: diferentes definições dos mesmos construtos. Psicologia: teoria e pesquisa, v. 17, n. 2, p. 151-159, 2001.

SHULMAN, L. S. El saber y entender de la profesión docente. Estudios públicos, n. 99, p. 195-224, 2005.

SUERTEGARAY, D. M. A. Geografia, ambiente e território. Revista da Casa da Geografia de Sobral (RCGS), v. 17, n. 3, p. 128-144, 2015. 


\section{REVISTA ELETRÔNICA}

DA GRADUAÇÃO/PÓS-GRADUAÇÃO EM EDUCAÇÃO

UFG/REJ

TARDIF, M. Saberes docentes e formação profissional. 6. ed. Petrópolis, RJ: Vozes, 2006.

UNESCO. Glossário De Terminologia Curricular. Disponível em

http://unesdoc.unesco.org/images/0022/002230/223059por.pdf acesso em 02/07/2016.

YOUNG, Michael. Para que servem as escolas? Educação \& Sociedade, v. 28, n. 101, 2007.

YOUNG, M. Superando a crise na teoria do currículo: uma abordagem baseada no conhecimento. Cadernos Cenpec| Nova série, v. 3, n. 2, 2014.

YOUNG, M.; MULLER, Johan. Três cenários educacionais para o futuro: lições da sociologia do conhecimento. Estudos em Avaliação Educacional, v. 27, n. 65, p. 522$551,2016$. 